\title{
Expression of Tumour Associated Transcripts in Malignant Melanoma Metastases - with Methodological Aspects
}

\author{
Malin Farnebäck ${ }^{1}$, Annika Håkansson², \\ Leif Håkansson 3 , Bertil Gustafsson ${ }^{4}$ and Bertil Kågedal ${ }^{1}$ \\ ${ }^{1}$ Department of Clinical and Experimental Medicine, Division of Clinical Chemistry, \\ ${ }^{2}$ Division of Diagnostics and Clinical Services, Skåne University Hospital \\ SE 20502 Malmö \\ ${ }^{3}$ Division of Oncology, Faculty of Health Sciences, Linköping University \\ SE-581 85 Linköping \\ ${ }^{4}$ Division of Pathology and Cytology, Faculty of Health Sciences, Linköping University \\ SE-581 85 Linköping \\ Sweden
}

\section{Introduction}

Several melanoma antigens, recognized by autologous cytotoxic $\mathrm{T}$ lymphocytes, have been identified (Boon and van der Bruggen, 1996). The antigens can be divided into two separate groups, (a) antigens associated with pigment formation such as tyrosinase (Wölfel et al., 1994), tyrosinase related protein (TRP)-1 (Wang et al., 1995), TRP-2 (Wang et al., 1996), MART-1/Melan-A (Coulie et al., 1994; Kawakami et al., 1994a) and gp100/Pmel 17 (Kawakami et al., 1994b) present in normal as well as malignant cells of melanocytic lineage, and (b) tumour associated antigens of the MAGE-, BAGE- and GAGE-families that are found in many different malignant cells (Brasseur et al., 1995). These antigens are presented on the cell surface by HLA class I molecules and are important in the immune surveillance of tumour cells and several of these antigens have been utilized in vaccination studies (Parmiani et al., 2002).

In addition to being investigated for their role in the immune response, mRNAs of these antigens, especially tyrosinase, have been used for detection of circulating melanoma cells in blood (Brownbridge et al., 2001; de Vries et al., 1999; Hoon et al., 1995; Johansson et al., 2000; Reynolds et al., 2003; Smith et al., 1991). In this context there are great variations in the results (for a review see (Keilholz et al., 1997)) and the usefulness of this technique is disputed (Hanekom et al., 1999; Mellado et al., 1999; Osella Abate et al., 2000). The variations may be due to several factors, e.g. differences in the methods used and in the selection of participating patients. Low concentrations of the transcripts in the tumours would be reflected in a low detection rate of melanoma cells in blood and high transcript concentrations would result in a higher probability of detecting cells present in blood.

Several of these antigens have earlier been studied by immunohistochemical and conventional RT-PCR methods. A great heterogeneity in the frequency of expression of 
tyrosinase, MART-1/Melan-A, and gp100/Pmel 17 protein in different melanocytic lesions and melanoma cell lines has been shown (Cormier et al., 1998; de Vries et al., 1997; Sarantou et al., 1997). Similarly, loss of mRNA expression of one or more of the antigens tyrosinase TRP-1, TRP-2, MART-1/Melan-A, and gp100/Pmel 17 was found in $26 \%$ of primary and metastatic tumours (Sarantou, et al., 1997). In addition, Dalerba et al. (Dalerba et al., 1998) found a variable mRNA expression of tyrosinase, MART-1/Melan-A, MAGE-A1, MAGEA2, MAGE-A3, BAGE and GAGE between multiple in-transit and lymph-node metastases. However, the above mentioned studies did not provide quantitative information. Thus, better understanding of mRNA levels and the factors influencing the expression of these antigens is needed.

We have therefore determined the mRNA concentrations of tyrosinase, TRP-1, TRP-2, MART-1/Melan-A, MAGE-A3, MAGE-A12, S-100 and $\mathrm{G}_{\mathrm{D} 2}$ synthase in sections of snap frozen melanoma metastases from treated and untreated patients. Furthermore, we have compared two different methods, use of section area and use of housekeeping genes for normalization of the expression data for differences in starting amounts of tissue. In addition, we have investigated the influence of tumour-infiltrating lymphocytes on the expression of these antigens.

\section{Material and methods}

\subsection{Tumour material}

Melanoma metastases from 7 women and 21 men with regional and systemic disease were investigated. The median age of the patients was 50 years (range 26 to 82 years) and treatment for metastatic disease was given to 15 of the patients before removal of the metastases. Recurrences were cytologically verified by fine needle aspiration biopsy before start of treatment. One metastasis from each patient was studied. In patients with systemic disease easily resectable metastases were chosen. In patients with regional disease, nonnecrotic biopsies were randomly chosen by the pathologist. Only sections of good technical quality were included in the study. Thus, sections that were either crackled or damaged, or contained large necrotic areas, or mainly contained lymph node remnants were excluded. The study was approved by the ethical committee at the University Hospital in Linköping, Sweden.

The treatment schedule was cisplatinum $30 \mathrm{mg} / \mathrm{m}^{2}$ i.v., dacarbazine (DTIC) $250 \mathrm{mg} / \mathrm{m}^{2}$ i.v. day 1-3 and interferon- $\alpha 2 \mathrm{~b} 10$ million IU s.c. three times weekly. The duration of each cycle was 28 days.

The tumours were snap frozen after resection and stored at $-70^{\circ} \mathrm{C}$ until further processed. Three parallel sections $(7 \mu \mathrm{m})$ were cut from each metastasis and two of them were immediately transferred to $500 \mu \mathrm{l}$ of lysis buffer (100 mM Tris-HCl pH 7.6, $500 \mathrm{mM} \mathrm{LiCl}, 10$ mM EDTA, $5 \mathrm{mM}$ DTT, 1\% SDS) and homogenized using a Mikro-Dismembrator S (B. Braun Biotech International GmbH, Melsungen Germany). The third section was used for conventional light microscopy studies.

\subsection{Analysis of mRNA expression}

The lysate was added to $100 \mu$ l GenoPrep mRNA Beads (GenoVision, Oslo, Norway) and the mixture was incubated on a rotating mixer for $10 \mathrm{~min}$. The magnetic beads were immobilized using a Dynal MPC-S device (Dynal Biotech, Oslo, Norway) and washed twice in $1 \mathrm{ml} 10 \mathrm{mM}$ Tris-HCl, pH 7.6, containing $150 \mathrm{mM} \mathrm{LiCl}, 1 \mathrm{mM}$ EDTA, and $0.1 \%$ SDS and 
then twice in $1 \mathrm{ml} 10 \mathrm{mM}$ Tris-HCl, $\mathrm{pH}$ 7.6, containing $150 \mathrm{mM} \mathrm{LiCl}$, and $1 \mathrm{mM}$ EDTA. mRNA was released from the magnetic beads in $20 \mu$ l RNase-free water by incubation at $70^{\circ} \mathrm{C}$ for $2 \mathrm{~min}$. First strand cDNA was synthesized using random hexamers and Moloney Murine Leukemia Virus reverse transcriptase as described earlier (Johansson, et al., 2000).

\begin{tabular}{llc}
\hline Oligonucleotide & Sequence & $\begin{array}{c}\text { Conc. } \\
\text { (nM) }\end{array}$ \\
\hline Tyrosinase FP & ATGGATAAAGCTGCCAATTTCA & 100 \\
Tyrosinase RP & GGCATCCGCTATCCCAGTA & 100 \\
Tyrosinase Probe & CTTTAGAAATACACTGGAAGGATTTGCTAGTCCAC & 50 \\
TRP-1 FP & TCATGAGGGACCAGCTTTTC & 100 \\
TRP-1 RP & TCTTGCAACATTTCCTGCAT & 100 \\
TRP-1 Probe & CACATGGCACAGGTACCACCACCT & 50 \\
TRP-2 FP & GGAAAGAGATCTCCAGCGAC & 100 \\
TRP-2 RP & ATCACACTCGTTCCTCCCA & 100 \\
TRP-2 Probe & TGCTTTGCCCTACTGGAACTTTGCC & 50 \\
MART-1/Melan-A FP & GCCACTCTTACACCACGGC & 100 \\
MART-1/Melan-A RP & TCCCAGGATCACTGTCAGGA & 100 \\
MART-1/Melan-A Probe & GCCGATCCCAGCGGCCTCTT & 100 \\
S-100 FP & CCATTTCTTAGAGGAAATCAAAGAG & 100 \\
S-100 RP & ATTCGCCGTCTCCATCAT & 100 \\
S-100 Probe & TGTCCAGTGTTTCCATGACTTTGTCCA & 100 \\
GD2 synthase FP & CCAGGGAGCCCAGTACAAC & 100 \\
GD2 synthase RP & GCCGTGAAGACGAAGTCG & 100 \\
GD2 synthase Probe & AACCAGCCCTTGCCGAAGGGC & 200 \\
MAGE-A3 FP & TGAGGAGGCAAGGTTCTGA & 100 \\
MAGE-A3 RP & ATGGAGACCCACTGGCAG & 100 \\
MAGE-A3 Probe & TCTGGTCCTCCAGGTCAGCCTGT & 100 \\
MAGE-A12 FP & GTGAGGAGGCAAGGTTCTG & 100 \\
MAGE-A12 RP & GGCATGATGACTCTGGTCAG & 100 \\
MAGE-A12 Probe & TCCTGCCCACACTCCTACCTGCT & 50 \\
\hline
\end{tabular}

Table 1. Sequences and concentrations of primers and probes used in real-time PCR for melanoma transcripts

\begin{tabular}{lll}
\hline Transcript & Forward primer & Reverse primer \\
\hline Tyrosinase & TTGGCAGATTGTCTGTAGCC & AGGCATTGTGCATGCTGCTT \\
TRP-1 & AAAGCTTTGGTGAAGTGGATT & AGACCACTCGCCATTGAGA \\
TRP-2 & CTACAGGGCCATAGATTTCTC & GTTGTAGTCATCCAAGCTATCAC \\
MART-1/Melan-A & GACTCTCATTAAGGAAGGTGTCC & TTGTTAAGGCACATTGAGTGC \\
S-100 & GGGAGACAAGCACAAGCTGAAG & TTCAAAGAACTCGTGGCAGGCAGT \\
GD2 synthase & CCAGGGAGCCCAGTACAAC & GCCGTGAAGACGAAGTCG \\
MAGE-A3 & TGAGGAGGCAAGGTTCTGA & ATGGAGACCCACTGGCAG \\
MAGE-A12 & GAGGTCAGAGAACAGCGAGATT & CCGCAGGGTGACTTCC \\
\hline
\end{tabular}

Table 2. Primers used for synthesis of calibrators

The cDNA was diluted 1:10 before further analysis. From these samples $2.5 \mu 1$ was analyzed in triplicates by PCR in a total volume of $25 \mu \mathrm{l}$ (Johansson, et al., 2000). 
The mRNAs of tyrosinase, TRP-1, TRP-2, MART-1/Melan-A, MAGE-A3, MAGE-A12, S-100, and $G_{D 2}$ synthase were analyzed by real-time PCR using the ABI Prism 7700 Sequence Detector System (Applied Biosystems, Foster City, California, USA). All transcripts were analyzed using the same protocol, $1 \times$ TaqMan PCR Buffer (Applied Biosystems), $5 \mathrm{mM}$ $\mathrm{MgCl}_{2}$ (Applied Biosystems), $200 \mu \mathrm{M}$ dNTPs (Amersham Biosciences, Uppsala, Sweden), and $0.025 \mathrm{U} / \mu \mathrm{l}$ AmpliTaq Gold (Applied Biosystems) (Johansson, et al., 2000) with the respective primer and probe concentration (Table 1). The oligonucleotides were bought from Scandinavian Gene Synthesis (Köping, Sweden). Their sequences are shown in Table 1.

For each transcript, a specific cDNA calibrator was synthesized using primers located outside the analytical primers (Table 2). The PCR product was quantified by limiting dilution and Poisson distribution as described earlier (Johansson et al., 2002). The calibrators were analyzed in ten-fold dilutions from 100000 to 10 transcripts/ $\mu 1$ in each PCR run.

Three different housekeeping genes, hypoxanthine ribosyl transferase (HPRT), $\beta$-glucuronidase (GUS) and $\beta_{2}$-microglobulin (B2M), were amplified using Pre-Developed Assay Reagents from Applied Biosystems. Serial dilutions of cDNA from IMR-32 neuroblastoma cells were used as calibrators. To be able to combine the three housekeeping genes to one normalization factor the expression data of each housekeeping gene need to be at the same level as the others. As the three housekeeping genes differed in their level of expression (Kågedal et al., 2007), a relative expression of each housekeeping gene was defined as the percentage expression of the individual metastasis compared with the mean of all metastases for each housekeeping gene. The mean of the relative expression of the three housekeeping genes was used for normalization. The calculation of the normalization factor (NF) is described by the following equation:

$$
N F_{i}=\left(\frac{x_{i H P R T}}{\bar{x}_{H P R T}} \cdot 100+\frac{x_{i G U S}}{\bar{x}_{G U S}} \cdot 100+\frac{x_{i B 2 M}}{\bar{x}_{B 2 M}} \cdot 100\right) / 3
$$

where $x_{i}$ is the expression of the respective housekeeping gene in the individual sample and $\bar{x}$ is the respective mean expression.
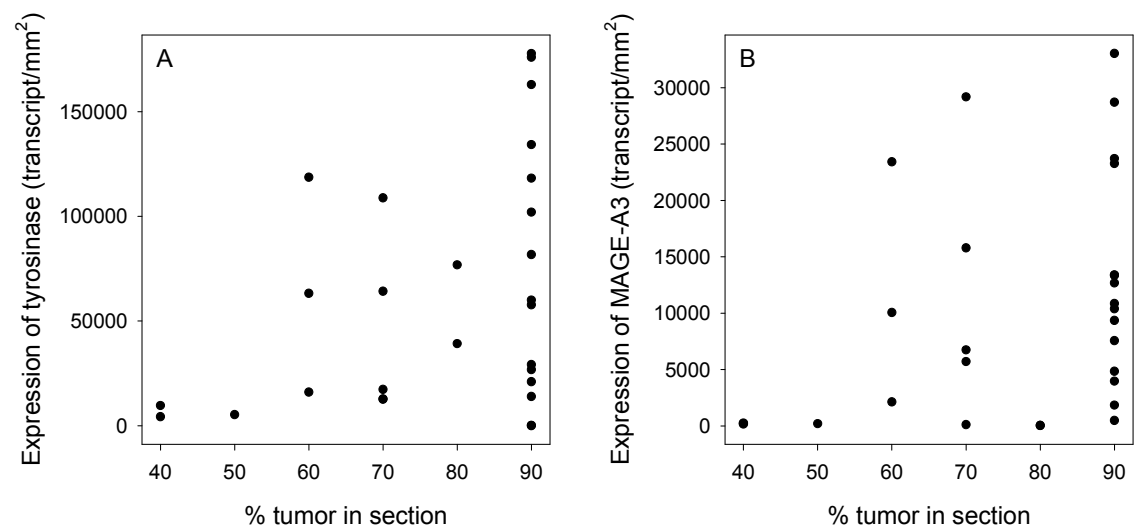

Fig. 1. Expression of tyrosinase (A) and TRP-1 (B) plotted against the tumour content of tissue section of melanoma metastases. The amounts of transcript are given normalized to the area of the respective section 


\subsection{Staining of sections and evaluation of tumour cells and lymphocytes}

The sections used for microscopy were stained with hematoxylin and eosin and mounted in Mountex (Histolab products AB, Göteborg, Sweden). The amounts of tumour-infiltrating lymphocytes were semi-quantitatively scored as $<5 \%, 5-10 \%, 10-15 \%, 15-20 \%$ and $>20 \%$. Metastases scored as $<5 \%$ were considered to contain low amounts of such cells. The amounts of tumour in the sections were also semi-quantitatively scored to the nearest decile. The scores were made by two independent observers (AH, BG). The sections were also photographed and the area of the sections was measured using the shareware NIH Image 1.63 (http:/ / rsb.info.nih.gov/nih-image/download.html).

\subsection{Statistics}

Correlations were evaluated using Pearson's correlation coefficient. The Mann-Whitney U-test was used to compare expression of melanoma associated antigens in sections with different amounts of tumour-infiltrating cells and in metastases from untreated and treated patients.

\section{Results}

The present study is based on analysis of melanoma associated transcripts in $7 \mu \mathrm{m}$ thick tissue sections from frozen melanoma metastases. Histological analysis of parallel section was performed and biopsies with necrotic areas and lymph node remnants of more than 30 per cent of the section area were not included. The amount of tumour cells was scored and found to vary between 40 per cent and more than 90 per cent of the section area.

\begin{tabular}{lrrrrrrrr}
\hline & \multicolumn{4}{c}{ aTranscripts/mm² } & \multicolumn{4}{c}{ bTranscripts/HKG } \\
& Mean & \multicolumn{2}{c}{ SD Median } & Range & Mean & SD Median & Range \\
\hline Tyrosinase & 61000 & 56000 & 48000 & $7-180000$ & 32000 & 24000 & 25000 & $9-94000$ \\
TRP-1 & 28000 & 57000 & 1600 & $0-210000$ & 11000 & 17000 & 1300 & $0-59000$ \\
TRP-2 & 65000 & 100000 & 16000 & $150-410000$ & 40000 & 65000 & 12000 & $130-260000$ \\
MART-1/Melan-A & 120000 & 120000 & 77000 & $520-450000$ & 63000 & 54000 & 45000 & $360-200000$ \\
S-100 & 91000 & 123000 & 45000 & $960-530000$ & 46000 & 63000 & 27000 & $6800-310000$ \\
GD2 synthase & 560 & 670 & 410 & $13-2900$ & 280 & 410 & 150 & $22-2200$ \\
MAGE-A3 & 10000 & 10000 & 8500 & $36-33000$ & 4800 & 4400 & 4300 & $36-21000$ \\
MAGE-A12 & 4300 & 5000 & 2100 & $0-18000$ & 1900 & 2200 & 1400 & $0-9800$ \\
\hline
\end{tabular}

aThe results were normalized to the area of the sections.

bThe results were normalized to the mean expression of the housekeeping genes (HKG) HPRT, GUS and $\mathrm{B} 2 \mathrm{M}$.

Table 3. Expression of melanoma-associated antigens in metastatic lesions

No significant correlations were found between any transcript concentration and the per cent tumour in the sections. This is illustrated in Fig. 1 for tyrosinase and MAGE-A3.

To account for differences in the amounts of starting material, the results of the mRNA analysis were normalized to the tissue section areas measured in parallel sections. The areas 
of the tumour sections varied between 7 and $124 \mathrm{~mm}^{2}$. For comparison the mean of three housekeeping genes was also used in order to normalize the transcript expression data.

For each transcript, there was a large variation between the metastases. Also the mean levels of the different transcripts varied greatly. The pigment-related transcripts (tyrosinase, TRP-1, TRP-2, and MART-1/Melan-A) and that of S-100 had the highest concentrations and widest range (Table 3). For TRP-1 and to some extent for TRP-2, the median was low compared to the mean, which was due to a very low expression in a high proportion of the metastases (Fig. 2). MAGE-A3 and MAGE-A12 were expressed at a somewhat narrower range, whereas $\mathrm{G}_{\mathrm{D} 2}$ synthase was expressed at even lower levels.
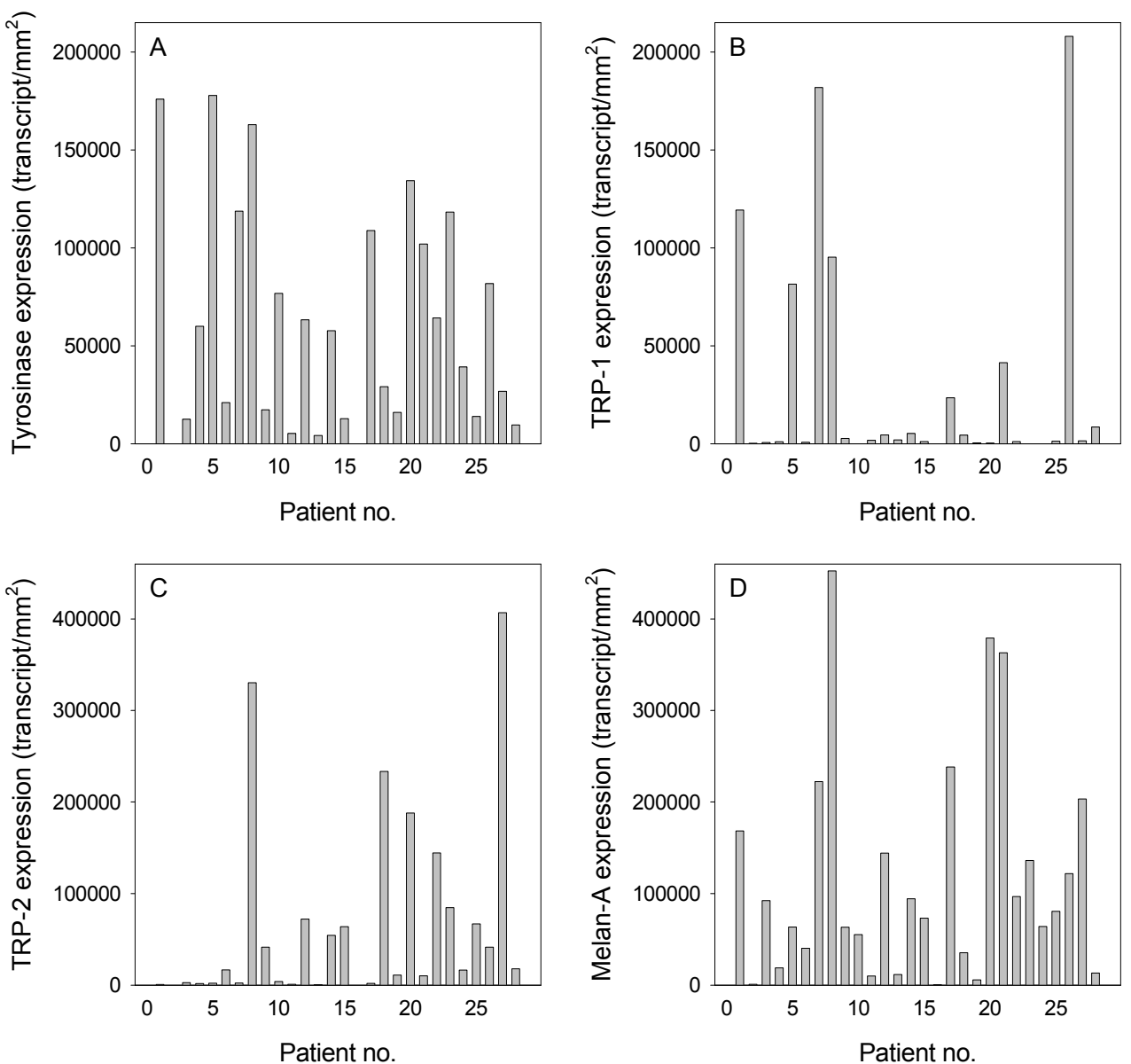

Fig. 2. Expression of (A) tyrosinase, (B) TPR-1, (C) TRP-2, and (D) MART-1/Melan-A mRNAs in frozen sections from malignant melanoma metastases $(n=28)$. The results are given normalized to the area of parallel tissue sections

When housekeeping genes were used for normalization, there was a tendency to less variation of the data, c.f. range of the data (Table 3). Fig. 3 shows the comparison of the two 
ways of normalization for tyrosinase and MAGE-A3 data of the metastases containing $90 \%$ tumour. It can be seen that some of the highest expressing metastases were equalized when housekeeping genes were used for normalization. Thus, there were transpositions in the orders regarding the amounts of transcripts depending on normalization. There were significant correlations $(\mathrm{p}<0.05)$ for all transcripts when normalized by the two methods, but there were great variations around the regression line (data not shown).
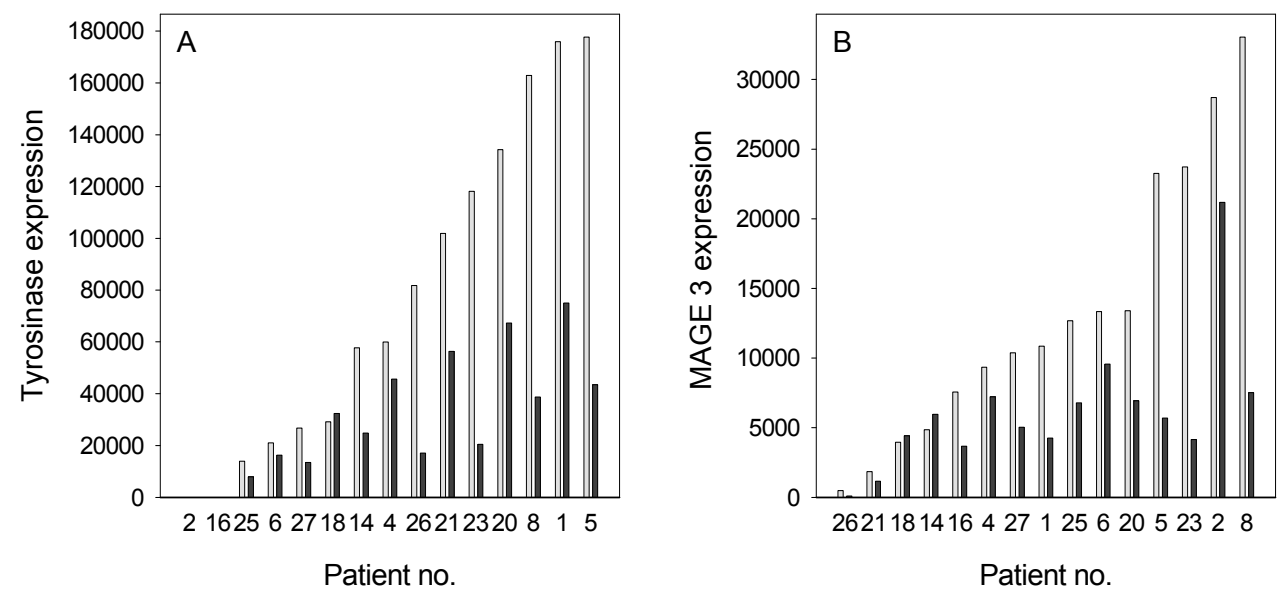

Fig. 3. Comparison of the two methods used for normalization of mRNA data, exemplified by (A) tyrosinase and (B) MAGE-A3 expression. The results normalized to area of the section (gray bars) and to the expression of the three housekeeping genes (black bars) are shown for the metastases containing $90 \%$ tumour. The metastases were sorted by the results normalized to area for each transcript

The correlations between the expressions of the different transcripts were examined. Among the pigment-related transcripts a strong correlation was found between tyrosinase and MART-1/Melan-A ( $p<0.001, R=0.67$, Fig. 4A). Weaker correlations $(p<0.01, R=0.57$ and $\mathrm{R}=0.49$ respectively) were found between the two pairs tyrosinase-TRP-1 and TPR-2-MART-1/Melan-A (data not shown). However, the appearance of these weaker correlations was mainly due to high expressions of these antigens in a few sections. The MAGE-antigens MAGE-A3 and MAGE-A12 also correlated strongly with each other $(\mathrm{p}<0.001, \mathrm{R}=0.76$, Fig. 4B). Interestingly when biopsies from treated and untreated patients were analyzed separately, MAGE-A3 was significantly correlated with tyrosinase and MART-1/Melan-A in the sections from the treated patients (Fig. 5, $\mathrm{p}<0.01, \mathrm{R}=0.66$ and 0.71 respectively).

When the total material was analyzed, the occurrence of tumour infiltrating lymphocytes did not seem to influence the expression of the genes (12 tumours contained low and 16 contained high amounts of tumour infiltrating lymphocytes). However, if only metastases from untreated patients were analyzed, there was a significantly lower $(p<0.05)$ expression of MART-1/Melan-A and S-100 in the metastases containing high amount of tumourinfiltrating lymphocytes ( $\mathrm{n}=5$ and $\mathrm{n}=8$ for low and high respectively, data not shown). These differences were not present in the treated patients. 

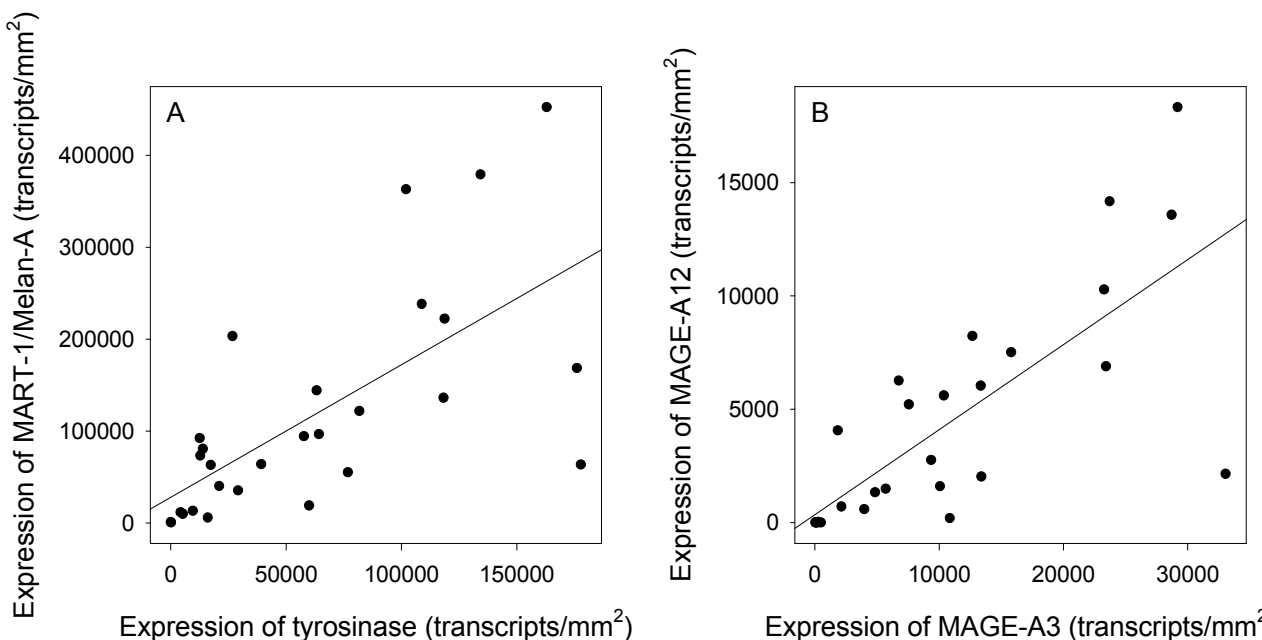

Expression of MAGE-A3 (transcripts $/ \mathrm{mm}^{2}$ )

Fig. 4. Correlations between (A) tyrosinase and MART-1/Melan-A expression, and between (B) MAGE-A3 and MAGE-A12 expression in melanoma metastases. The expression data were normalized to the section area

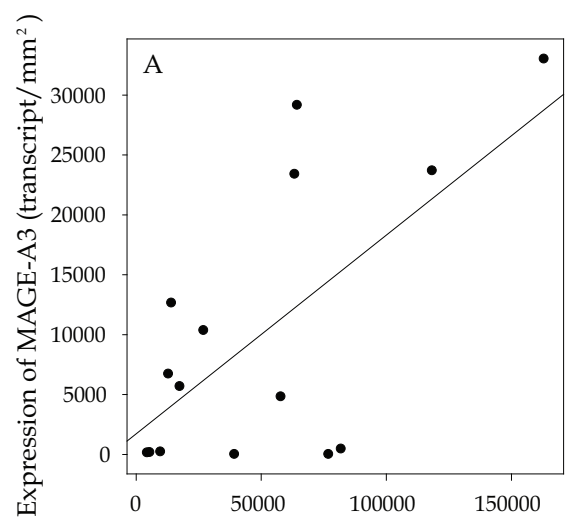

Expression of tyrosinase (transcript $/ \mathrm{mm}^{2}$ )

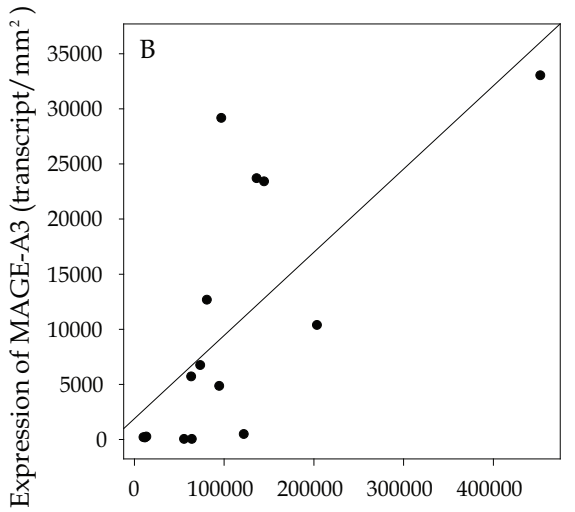

Expression of MART-1/Melan-A (transcript/ $\mathrm{mm}^{2}$ )

Fig. 5. Correlations of MAGE-A3 with (A) tyrosinase and (B) MART-1/Melan-A in treated patients $(n=15)$. The expression data were normalized to the section area to account for differences in starting amount

The influence of treatment on the mRNA expression was also investigated (Table 4). A significant effect was obtained in TRP-2 expression, where the treated tumours $(n=15)$ showed an increased expression $(\mathrm{p}<0.05)$ as compared with the untreated tumours $(\mathrm{n}=13)$. The $G_{D 2}$ synthase expression on the other hand was decreased in the treated group $(p<0.05)$. With all other transcripts, no significant differences were found.

As the tumour-infiltrating lymphocytes could be of importance for the expression of the antigens, we substratified the sections according to low or high infiltration of tumour- 
infiltrating lymphocytes ( $<5 \%$ was used as cut-off) before comparing data from untreated and treated patients (Table 4). No difference in TRP-2 expression was found in any of the groups. With $\mathrm{G}_{\mathrm{D} 2}$ synthase, the decrease in the treated patients remained in the metastases containing high amounts of tumour-infiltrating lymphocytes. For the other genes the only difference found was in tyrosinase expression, which was decreased in metastases from treated patients, but only in metastases containing low amounts of tumour-infiltrating lymphocytes. In table 4 the results are also given normalized by housekeeping genes. In addition to the differences found when normalized by area, increased expression of tyrosinase, MART-1/Melan-A, and S-100 in treated patients were found in the metastases containing high amounts of tumour-infiltrating lymphocytes.

\begin{tabular}{lllllll}
\hline & \multirow{2}{*}{ All metastases } & \multicolumn{2}{c}{ Tumour-infiltrating } & \multicolumn{2}{c}{$\begin{array}{l}\text { Tumour-infiltrating } \\
\text { lymphocytes low }\end{array}$} & \multicolumn{2}{l}{$\begin{array}{l}\text { lymphocytes high } \\
\text { lym }\end{array}$} \\
& $\mathrm{Tr} / \mathrm{mm}^{2}$ & $\mathrm{Tr} / \mathrm{HKG}$ & $\mathrm{Tr} / \mathrm{mm}^{2}$ & $\mathrm{Tr} / \mathrm{HKG}$ & $\mathrm{Tr} / \mathrm{mm}^{2}$ & $\mathrm{Tr} / \mathrm{HKG}$ \\
\hline Tyrosinase & $\mathrm{NS}^{\mathrm{d}}$ & $\mathrm{NS}$ & $\downarrow \mathrm{p}=0.010$ & $\downarrow \mathrm{p}=0.030$ & $\mathrm{NS}$ & $\uparrow \mathrm{p}=0.050$ \\
TRP-1 & $\mathrm{NS}$ & $\mathrm{NS}$ & $\mathrm{NS}$ & $\mathrm{NS}$ & $\mathrm{NS}$ & $\mathrm{NS}$ \\
TRP-2 & $\uparrow \mathrm{p}=0.019$ & $\uparrow \mathrm{p}=0.003$ & $\mathrm{NS}$ & $\uparrow \mathrm{p}=0.048$ & $\mathrm{NS}$ & $\mathrm{NS}$ \\
MART-1/Melan-A & $\mathrm{NS}$ & $\mathrm{NS}$ & $\mathrm{NS}$ & $\mathrm{NS}$ & $\mathrm{NS}$ & $\uparrow \mathrm{p}=0.021$ \\
S-100 & $\mathrm{NS}$ & $\mathrm{NS}$ & $\mathrm{NS}$ & $\mathrm{NS}$ & $\mathrm{NS}$ & $\uparrow \mathrm{p}=0.003$ \\
GD2 synthase & $\downarrow \mathrm{p}=0.010$ & $\downarrow \mathrm{p}=0.065$ & $\mathrm{NS}$ & $\mathrm{NS}$ & $\downarrow \mathrm{p}=0.007$ & $\downarrow \mathrm{p}=0.028$ \\
MAGE-A3 & $\mathrm{NS}$ & $\mathrm{NS}$ & $\mathrm{NS}$ & $\mathrm{NS}$ & $\mathrm{NS}$ & $\mathrm{NS}$ \\
MAGE-A12 & $\mathrm{NS}$ & $\mathrm{NS}$ & $\mathrm{NS}$ & $\mathrm{NS}$ & $\mathrm{NS}$ & $\mathrm{NS}$ \\
\hline
\end{tabular}

aThe material comprised of 13 metastases from untreated patients and 15 metastases from treated patients. The results were normalized to the area of each section or to the mean expression of three housekeeping genes (HKG) as indicated.

bMetastases containing $<5 \%$ tumour-infiltrating lymphocytes, 5 metastases from untreated patients and 7 metastases from treated patients.

cMetastases containing $\geq 5 \%$ tumour-infiltrating lymphocytes, 8 metastases from untreated patients and 8 metastases from treated patients.

dNS = not significant. Significant increases and decreases in the treated patients compared with untreated patients are indicated by arrows.

Table 4. Changes in the expression of melanoma associated transcripts in relation to treatment

\section{Discussion}

In gene expression studies the expression of specific transcripts is generally normalized to the expression of a housekeeping gene (Vandesompele et al., 2002). The rationale for simultaneous analysis of housekeeping genes is to compensate for different amounts of tissue taken to analysis, and for variations in the analytical process, e.g. degradation of mRNA, incomplete extraction etc. Usually housekeeping genes are chosen among genes of fundamental importance for cell metabolism and thus are supposed to be equally expressed in all cell types. However, there is no guarantee that they are adequate for normalization of transcripts in tumour studies as the metabolic and proliferative rates of tumours usually vary considerably with no relation to the expression of specific transcripts. Furthermore, tumour biopsies are usually heterogeneous partly due to the presence of cell types other than tumour cells, e.g. connective tissue and inflammatory cells. Housekeeping gene transcripts derived from such cells will of course limit the value of normalization of the 
selected tumour cell transcripts, i.e. as a measurement of the amount of tumour cells taken to analysis. In addition, housekeeping genes might vary between different cell types and also between tumours (Lee et al., 2002; Vandesompele, et al., 2002), not necessarily in relation with the occurrence of tumour specific transcripts. Therefore, in the present study on the expression of melanoma associated transcripts, we have reported the transcript data normalized by the area of parallel tissue sections with defined thickness $(7 \mu \mathrm{m})$.

Based on histological examination, necrotic tumours and tumours with lymph node remnants of more than 30 per cent of the tissue section area were excluded from this material. The percentage of the tissues section areas comprised by tumour was also determined in this analysis and no correlation was found between expression of transcripts and the amount of tumour cells. This shows that the dominating source of variation of expression of tumour associated transcripts is due to individual variation between different tumour cell populations. In the present material of melanoma metastases we found that the housekeeping genes HPRT, GUS and B2M varied greatly between melanoma metastases, and in several cases with a large discrepancy between the genes when normalized to the area of the tissue sections (unpublished results). There can be several reasons for this variation besides variation in the composition of the biopsies analyzed. Housekeeping genes might be modulated by cytokines produced by inflammatory cells or by agents used in the treatment of the tumour. However, as housekeeping genes are usually used in these type of studies, we have also analyzed the transcript data normalized to the mean of the three housekeeping genes. Interestingly, a significant correlation between the two methods was found for all transcripts analyzed and the outcome of the statistical analysis when normalized to housekeeping genes was not as different from that obtained when using the section area as might be expected. A significant correlation between tyrosinase-MART-1/Melan-A and MAGE-A3MAGE-A12 was also found when the transcript expression data were normalized to the housekeeping genes. The effect of tumour infiltrating lymphocytes on MART-1/Melan-A expression found in metastases from untreated patient remained. This was not the case with S-100 expression. Similarly, the differences found in the comparison of metastases from untreated and treated metastases when normalized to the section area were also found when data were normalized to the housekeeping genes. However, when using housekeeping genes, treatment related increases of tyrosinase, MART-1/Melan-A and S100 expression were found in metastases containing tumour-infiltrating lymphocytes. These differences were also seen as weak tendencies, when the section area was used for normalization.

As could be expected a wide variation in the expression of melanoma associated antigens between tumours was found irrespective of the method used for normalization. Similar results have also been reported by others (Ohnmacht et al., 2001; Riker et al., 2000). The difference in mRNA levels between the markers and tumours could be of importance for the detection of circulating melanoma cells in patients. A higher expression of transcript in each melanoma cell would facilitate the detection of transcripts in blood originating from a few circulating tumour cells. We found higher concentrations of the pigment-related transcripts than of the MAGE transcripts. These results could explain why patients are positive for tyrosinase more frequently than for MAGE-A3 in most studies analyzing several different melanoma markers (Berking et al., 1999; Hoon et al., 2000; Hoon, et al., 1995). One exception was reported by Reynolds et al. (Reynolds, et al., 2003), who detected MAGE-A3 mRNA in a slightly higher proportion of the patients than tyrosinase mRNA.

Several mechanisms are likely to be involved in regulation of the expression of melanoma associated transcripts. We found a strong correlation between tyrosinase and 
MART-1/Melan-A. This could perhaps be explained by the findings that both tyrosinase (Bentley et al., 1994; Yasumoto et al., 1994) and MART-1/Melan-A (Du et al., 2003) transcription is regulated by the microphtalmia transcription factor (MITF). MITF is also believed to be involved in the regulation of TRP-1 and TRP-2 (Yasumoto et al., 1997), however these two genes have also been reported to be regulated independently of tyrosinase (Fang et al., 2001; Fang and Setaluri, 1999). Thus, other mechanisms may be involved in the regulation of TRP-1 and TRP-2 expression. This may be the reason why the expression of the pigment-related transcripts was not strongly correlated with each other in the metastases studied here. Also the expression of the two MAGE transcripts, MAGE-A3 and MAGE-A12, were strongly correlated with each other in the present study. Eradication of immunogenic tumour cell clones either spontaneously or induced by immunotherapy will change the occurrence of tumour associated antigens. The mRNA concentrations of these antigens are likely to be of importance for the presentation of antigens to the immune system, provided that there is a quantitative relation between mRNA and protein expression. A correlation between mRNA expression and recognition by cytotoxic $\mathrm{T}$ lymphocytes has been shown for gp100/Pmel17 (Riker, et al., 2000). Interestingly, there seemed to be a relation between the stage of the patient and the occurrence of tyrosinase and MAGE-A3. The detection rate of tyrosinase mRNA was higher in advanced melanoma whereas the detection rate of MAGE-A3 mRNA was higher in the earlier stages (Reynolds, et al., 2003). Furthermore, down regulation of tyrosinase and TRP-2 has been shown to correlate with a shorter survival (Takeuchi et al., 2003).

Tumour cells have developed several mechanisms for immune escape. One way is a reduced presentation of antigens in HLA class I (Ohnmacht and Marincola, 2000). This can be accomplished either by down regulation of HLA or a decreased expression of the presented antigens. Immunohistochemical studies showed that vaccination with gp100 peptide decreased the expression of gp100 in metastatic lesions (Riker et al., 1999). When vaccination with gp100 was combined with IL-2 treatment, a decrease was also observed in MART-1/Melan-A expression. In contrast to these findings, it was reported that MART$1 /$ Melan-A was expressed in a stable manner, as assessed by immunohistochemistry, in serial fine needle aspirates from melanoma patients undergoing peptide vaccination (Fetsch et al., 2001). However, studies on gene expression from repeated fine needle aspirates showed that gp100, MART-1/Melan-A and TRP-2 decreased after vaccination treatment, but only in the patients responding to treatment (Ohnmacht, et al., 2001). This might be due to differences in the sensitivity of the two methods and might still be compatible with eradication of the antigen positive clones. In the present study, only tyrosinase and $G_{\mathrm{D} 2}$ synthase expressions were decreased in treated melanomas compared to untreated. However, for tyrosinase this effect was found only in metastases that did not recruit lymphocytes.

Apart from down regulation or selection due to immune mediated anti-tumour reactivity, the expression of melanoma antigens could be modulated by several other factors. The presence of tumour-infiltrating lymphocytes could affect the expression. Activated lymphocytes secrete various types of cytokines, which are involved in regulatory processes. It was shown that interferon- $\gamma$ up-regulated tyrosinase and MAGE-A3 in 4/10 and 4/18 cell lines (Hofbauer et al., 2001). This might explain why a treatment related down regulation of tyrosinase was found only in tumours with low numbers of tumour infiltrating lymphocytes since interferon- $\gamma$ produced by a high number of tumour-infiltrating lymphocytes might have up regulated tyrosinase (Hofbauer et al., 2001). 
The drugs used for treatment could either modulate the mRNA expression or perhaps select clones with an altered expression. The patients in this study were treated with cisplatinum, DTIC, and interferon- $\alpha$. Interferons have been shown to give mixed responses in the regulation of melanoma associated antigens in melanoma cultures. Interferon- $\alpha$ up regulated the expression of MAGE-A3 more than $50 \%$ in 5 of 18 melanoma cell cultures (Hofbauer et al., 2001). In the remaining cell lines the expression was either not affected or slightly decreased. In our study, however, there was no effect of treatment on the MAGE transcripts, which might be due to a possible up-regulation being counteracted by eradication of MAGE-A3 positive clones. This multi-factorial regulation of antigen expression can also explain why a correlation between MAGE-A3 expression and tyrosinase and MART-1/MelanA expression in the present study was found only in treated patients.

It has also been speculated that some of the studied antigens can contribute to drug resistance. Hence, a selection of highly expressing clones would be expected. Elevated expression of several members of the MAGE and GAGE gene families have been found in paclitaxel resistant cell lines (Duan et al., 2003). Similarly, Pak et al. (Pak et al., 2000) have shown that melanoma cell lines resistant to cisplatinum had elevated levels of TPR-2. The resistance was independent of the expression of the other two transcripts of the tyrosinase family and no correlation was found between the melanin content of the cell lines and resistance. Thus, it was concluded that the protection against cisplatinum cytotoxicity is mediated through TRP-2 rather than through melanin. This observation can explain the treatment-related up-regulation of TRP-2 as the activity of cisplatinum is of importance for the therapeutic effect of the combination treatment given in the present study. TRP-2 positive clones are thus likely to be protected from therapeutic eradication.

Quantitative analysis of melanoma associated transcripts in tumour material is very complex partly because of problems in selection and use of housekeeping genes as discussed above and partly because of the complex regulation of the expression of these transcripts by cytokines produced by tumour infiltrating inflammatory cells and by the modulatory effects of therapeutic drugs. This study demonstrates that after all it is possible by careful analysis of the data to obtain biologically relevant results.

\section{Conclusion}

Several antigens expressed in malignant melanoma are involved in the immunological surveillance of the tumour. The mRNAs of these antigens, especially tyrosinase, have also been used in the detection of minimal residual disease in the blood of melanoma patients. We have therefore analyzed the expression of tyrosinase, TRP-1, TRP-2, MART-1/Melan-A, MAGE-A3, MAGE-A12, S-100 and $\mathrm{G}_{\mathrm{D} 2}$ synthase by real-time PCR in snap frozen sections from 28 regional and systemic metastases. Treatment with cisplatinum, dacarbazine and interferon- $\alpha 2 b$ was given to 15 patients before surgery. The transcript concentrations varied widely between individual metastases. However, in general the pigment-related transcripts and that of S-100 were found at higher levels than those of MAGE-A3, MAGE-A12 and GD2 synthase. Significant correlations $(p<0.001)$ were found between tyrosinase and MART1/Melan-A and between MAGE-A3 and MAGE-A12. TRP-2 and GD2 synthase were both influenced by the treatment, TRP-2 expression was increased in the metastases from treated patients, whereas $G_{D 2}$ synthase expression was decreased. Furthermore, a decrease in tyrosinase expression was found in metastases without tumour-infiltrating lymphocytes. In this work normalization by the section area contra normalization by housekeeping genes was also evaluated and similar results were obtained with the two methods. 
The regulation of the expression of tumour associated transcripts is complex and multifactorial and different factors could produce counteracting effects. This study, however, demonstrates that by careful analysis of the data it is possible to obtain biologically relevant results.

\section{Acknowledgment}

We would like to thank Prof. John Carstensen, Oncological Center, Linköping University Hospital for statistical advice.

\section{References}

Bentley, N. J., Eisen, T., and Goding, C. R. (1994). Mol Cell Biol 14, 7996-8006.

Berking, C., Schlupen, E. M., Schrader, A., Atzpodien, J., and Volkenandt, M. (1999). Arch Dermatol Res 291, 479-84.

Boon, T., and van der Bruggen, P. (1996). J Exp Med 183, 725-9.

Brasseur, F., Rimoldi, D., Lienard, D., Lethe, B., Carrel, S., Arienti, F., Suter, L., Vanwijck, R., Bourlond, A., Humblet, Y., and et al. (1995). Int J Cancer 63, 375-80.

Brownbridge, G. G., Gold, J., Edward, M., and MacKie, R. M. (2001). Br J Dermatol 144, 279-87.

Cormier, J. N., Hijazi, Y. M., Abati, A., Fetsch, P., Bettinotti, M., Steinberg, S. M., Rosenberg, S. A., and Marincola, F. M. (1998). Int J Cancer 75, 517-24.

Coulie, P. G., Brichard, V., Van Pel, A., Wolfel, T., Schneider, J., Traversari, C., Mattei, S., De Plaen, E., Lurquin, C., Szikora, J. P., Renauld, J. C., and Boon, T. (1994). J Exp Med 180, 35-42.

Dalerba, P., Ricci, A., Russo, V., Rigatti, D., Nicotra, M. R., Mottolese, M., Bordignon, C., Natali, P. G., and Traversari, C. (1998). Int J Cancer 77, 200-4.

de Vries, T. J., Fourkour, A., Punt, C. J., van de Locht, L. T., Wobbes, T., van den Bosch, S., de Rooij, M. J., Mensink, E. J., Ruiter, D. J., and van Muijen, G. N. (1999). Br J Cancer 80, 883-91.

de Vries, T. J., Fourkour, A., Wobbes, T., Verkroost, G., Ruiter, D. J., and van Muijen, G. N. (1997). Cancer Res 57, 3223-9.

Du, J., Miller, A. J., Widlund, H. R., Horstmann, M. A., Ramaswamy, S., and Fisher, D. E. (2003). Am J Pathol 163, 333-43.

Duan, Z., Duan, Y., Lamendola, D. E., Yusuf, R. Z., Naeem, R., Penson, R. T., and Seiden, M. V. (2003). Clin Cancer Res 9, 2778-85.

Fang, D., Kute, T., and Setaluri, V. (2001). Pigment Cell Res 14, 132-9.

Fang, D., and Setaluri, V. (1999). Biochem Biophys Res Commun 256, 657-63.

Fetsch, P. A., Steinberg, S. M., Riker, A. I., Marincola, F. M., and Abati, A. (2001). Cancer 93, 409-14.

Hanekom, G. S., Stubbings, H. M., Johnson, C. A., and Kidson, S. H. (1999). Melanoma Res 9, 465-73.

Hofbauer, G. F., Geertsen, R., Laine, E., Burg, G., and Dummer, R. (2001). Melanoma Res 11, 213-8.

Hoon, D. S., Bostick, P., Kuo, C., Okamoto, T., Wang, H. J., Elashoff, R., and Morton, D. L. (2000). Cancer Res 60, 2253-7.

Hoon, D. S., Wang, Y., Dale, P. S., Conrad, A. J., Schmid, P., Garrison, D., Kuo, C., Foshag, L. J., Nizze, A. J., and Morton, D. L. (1995). J Clin Oncol 13, 2109-16. 
Johansson, M., Takasaki, A., Lenner, L., Årstrand, K., and Kågedal, B. (2002). Melanoma Res 12, 193-200.

Johansson, M., Årstrand, K., Håkansson, A., Lindholm, C., and Kågedal, B. (2000). Melanoma Res 10, 213-22.

Kawakami, Y., Eliyahu, S., Delgado, C. H., Robbins, P. F., Rivoltini, L., Topalian, S. L., Miki, T., and Rosenberg, S. A. (1994a). Proc Natl Acad Sci U S A 91, 3515-9.

Kawakami, Y., Eliyahu, S., Delgado, C. H., Robbins, P. F., Sakaguchi, K., Appella, E., Yannelli, J. R., Adema, G. J., Miki, T., and Rosenberg, S. A. (1994b). Proc Natl Acad Sci U S A 91, 6458-62.

Keilholz, U., Willhauck, M., Scheibenbogen, C., de Vries, T. J., and Burchill, S. (1997). Melanoma Res 7 Suppl 2, S133-41.

Kågedal, B., Farnebäck, M., Håkansson, A., Gustafsson, B., and Håkansson, L. (2007). Clin Chem Lab Med 45, 1481-7.

Lee, P. D., Sladek, R., Greenwood, C. M., and Hudson, T. J. (2002). Genome Res 12, 292-7.

Mellado, B., Gutierrez, L., Castel, T., Colomer, D., Fontanillas, M., Castro, J., and Estape, J. (1999). Clin Cancer Res 5, 1843-8.

Ohnmacht, G. A., and Marincola, F. M. (2000). J Cell Physiol 182, 332-8.

Ohnmacht, G. A., Wang, E., Mocellin, S., Abati, A., Filie, A., Fetsch, P., Riker, A. I., Kammula, U. S., Rosenberg, S. A., and Marincola, F. M. (2001). J Immunol 167, 1809-20.

Osella Abate, S., Savoia, P., Cambieri, I., Salomone, B., Quaglino, P., and Bernengo, M. G. (2000). Melanoma Res 10, 545-55.

Pak, B. J., Li, Q., Kerbel, R. S., and Ben-David, Y. (2000). Melanoma Res 10, 499-505.

Parmiani, G., Castelli, C., Dalerba, P., Mortarini, R., Rivoltini, L., Marincola, F. M., and Anichini, A. (2002). J Natl Cancer Inst 94, 805-18.

Reynolds, S. R., Albrecht, J., Shapiro, R. L., Roses, D. F., Harris, M. N., Conrad, A., Zeleniuch-Jacquotte, A., and Bystryn, J. C. (2003). Clin Cancer Res 9, 1497-502.

Riker, A., Cormier, J., Panelli, M., Kammula, U., Wang, E., Abati, A., Fetsch, P., Lee, K. H., Steinberg, S., Rosenberg, S., and Marincola, F. (1999). Surgery 126, 112-20.

Riker, A. I., Kammula, U. S., Panelli, M. C., Wang, E., Ohnmacht, G. A., Steinberg, S. M., Rosenberg, S. A., and Marincola, F. M. (2000). Int J Cancer 86, 818-26.

Sarantou, T., Chi, D. D., Garrison, D. A., Conrad, A. J., Schmid, P., Morton, D. L., and Hoon, D. S. (1997). Cancer Res 57, 1371-6.

Smith, B., Selby, P., Southgate, J., Pittman, K., Bradley, C., and Blair, G. E. (1991). Lancet 338, 1227-9.

Takeuchi, H., Kuo, C., Morton, D. L., Wang, H. J., and Hoon, D. S. (2003). Cancer Res 63, 441-8.

Vandesompele, J., De Preter, K., Pattyn, F., Poppe, B., Van Roy, N., De Paepe, A., and Speleman, F. (2002). Genome Biol 3, RESEARCH0034.

Wang, R. F., Appella, E., Kawakami, Y., Kang, X., and Rosenberg, S. A. (1996). J Exp Med 184, 2207-16.

Wang, R. F., Robbins, P. F., Kawakami, Y., Kang, X. Q., and Rosenberg, S. A. (1995). J Exp Med 181, 799-804.

Wölfel, T., Van Pel, A., Brichard, V., Schneider, J., Seliger, B., Meyer zum Büschenfelde, K. H., and Boon, T. (1994). Eur J Immunol 24, 759-64.

Yasumoto, K., Yokoyama, K., Shibata, K., Tomita, Y., and Shibahara, S. (1994). Mol Cell Biol 14, 8058-70.

Yasumoto, K., Yokoyama, K., Takahashi, K., Tomita, Y., and Shibahara, S. (1997). J Biol Chem 272, 503-9. 


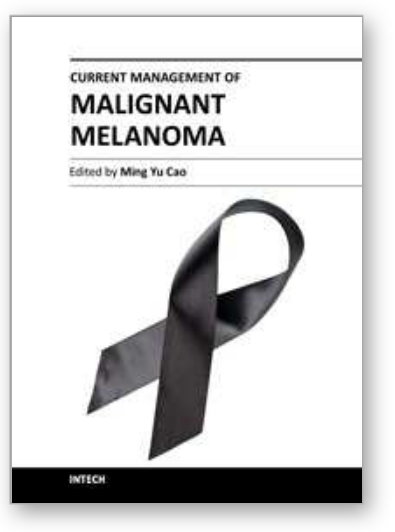

\author{
Current Management of Malignant Melanoma \\ Edited by Dr. Ming Yu Cao
}

ISBN 978-953-307-264-7

Hard cover, 274 pages

Publisher InTech

Published online 22, September, 2011

Published in print edition September, 2011

Management of melanoma is challenging, especially for the late stage of the disease. Development of new therapies and optimizing current treatments are being pursued in attempt to further improve the survival rate. The book provides up-to-date knowledge and experience in early diagnosis, prevention and treatment of melanoma as well as current ongoing clinical studies on melanoma. The book also provides the most recent perspectives of research on the molecular basis of melanoma, such as melanoma associated genes and a possible link between stress and melanoma.

\title{
How to reference
}

In order to correctly reference this scholarly work, feel free to copy and paste the following:

Malin Farnebäck, Annika Håkansson, Leif Håkansson, Bertil Gustafsson and Bertil Kågedal (2011). Expression of Tumour Associated Transcripts in Malignant Melanoma Metastases - with Methodological Aspects, Current Management of Malignant Melanoma, Dr. Ming Yu Cao (Ed.), ISBN: 978-953-307-264-7, InTech, Available from: http://www.intechopen.com/books/current-management-of-malignant-melanoma/expression-of-tumourassociated-transcripts-in-malignant-melanoma-metastases-with-methodological-asp

\section{INTECH}

open science | open minds

\section{InTech Europe}

University Campus STeP Ri Slavka Krautzeka 83/A 51000 Rijeka, Croatia Phone: +385 (51) 770447

Fax: +385 (51) 686166 www.intechopen.com

\section{InTech China}

Unit 405, Office Block, Hotel Equatorial Shanghai No.65, Yan An Road (West), Shanghai, 200040, China 中国上海市延安西路65号上海国际贵都大饭店办公楼405单元 Phone: +86-21-62489820

Fax: +86-21-62489821 
(C) 2011 The Author(s). Licensee IntechOpen. This chapter is distributed under the terms of the Creative Commons Attribution-NonCommercialShareAlike-3.0 License, which permits use, distribution and reproduction for non-commercial purposes, provided the original is properly cited and derivative works building on this content are distributed under the same license. 